\title{
Processo de morte e morrer: evidências da literatura científica de Enfermagem
}

\author{
Death and dying process: evidences from the literature of nursing
}

Proceso de la muerte y del morir: evidencias de la literatura de Enfermería

\section{Fernando José Guedes da Silva Júnior', Lissandra Chaves de Sousa Santos", Pedro Victor dos Santos Moura'II, Belisa Maria Silva Melo', Claudete Ferreira de Souza Monteiro' ${ }^{\text {IV }}$}

\author{
' Universidade Federal do Piauí, Curso de Enfermagem, Grupo de Estudos sobre Enfermagem, \\ Violência e Saúde Mental. Teresina-PI, Brasil. \\ "Faculdade de Saúde, Ciências Humanas e Tecnológicas do Piauí, Curso de Enfermagem, \\ Grupo de Estudos sobre Enfermagem, Violência e Saúde Mental. Teresina-PI, Brasil. \\ III Universidade Federal do Piauí, Curso de Medicina, Grupo de Estudos sobre Enfermagem, \\ Violência e Saúde Mental. Teresina-Pl, Brasil. \\ "v Universidade Federal do Piauí, Curso de Enfermagem, Programa de Pós-Graduação Mestrado em Enfermagem, \\ Grupo de Estudos sobre Enfermagem, Violência e Saúde Mental. Teresina-PI, Brasil.
}

Submissão: 04-08-2010 Aprovação: 27-01-2012

\section{RESUMO}

Objetivou-se identificar o perfil das produções e analisar percepções, sentimentos e intervenções efetivas diante o processo de morte e morrer no exercício profissional evidenciados na produção científica da enfermagem no período de 1994 a 2009. Realizou-se uma pesquisa qualitativa, descritiva, por meio de uma revisão sistemática da literatura com metassíntese a partir do método meta-etnográfico. Dez pesquisas atenderam os critérios de inclusão, este conjunto foi submetido à avaliação de qualidade com check list Critical Appraisal Skills Programme. Os sujeitos percebem este processo como passagem, separação e finitude. Este está permeado de sentimentos de frustração e impotência e as intervenções mais efetivas diante deste problema é o desenvolvimento de estratégias de enfrentamento que variam de acordo com a realidade de cada indivíduo.

Descritores: Morte; Tanatologia; Enfermagem baseada em evidências.

\begin{abstract}
The objective was to identify the profile of production and analyze perceptions, feelings and confrontations on the process of death and dying in the practice evidenced in nursing scientific production in the period 1994 to 2009. There was a qualitative, descriptive research, developed through a systematic literature review with metasynthesis from the meta-ethnographic method. Ten studies met the inclusion criteria, this set was subjected to quality assessment checklist with Critical Appraisal Skills Programme. Subjects perceive this process as a transition, separation and finitude. This is permeated with feelings of frustration and powerlessness and the most effective interventions to this issue is the development of coping strategies that vary with the reality of each individual.
\end{abstract}

Key words: Death; Thanatology; Evidence-based nursing.

\section{RESUMEN}

El objetivo fue identificar el perfil de la producción y analizar las percepciones, los sentimientos y las confrontaciones en el proceso de muerte y el morir en la práctica se evidencia en la producción científica de enfermería en el período 1994 a 2009. Hubo una investigación cualitativa, descriptiva, desarrollada a través de una revisión sistemática de la literatura con metasíntesis del método meta-etnográfico. Diez estudios cumplieron los criterios de inclusión, este conjunto fue sometido a evaluación de la calidad con la lista de valoración crítica de las habilidades. Los sujetos perciben este proceso como una transición, la separación y la finitud. Esto está impregnado de sentimientos de frustración e impotencia y las intervenciones más eficaces para este problema es el desarrollo de estrategias de afrontamiento que varían con la realidad de cada individuo.

Palabras clave: Muerte; Tanatología; Enfermería basada en la evidencia. 


\section{INTRODUÇÃO}

A temática da morte e o processo de morrer, intrínseco a ela, residem atualmente no ideário coletivo das sociedades ocidentais, sendo propalados indiscriminadamente por veículos de comunicação de larga natureza. A morte é a notícia mais frequente ${ }^{(1)}$, destacando-se os casos nos quais o delinear do morrer se sucede em completo anonimato, na solidão, sem cuidados, em substância, sem uma presença amiga que possa propiciar o aconchego de uma relação humana aliado a cuidados embasados em conhecimentos científicos.

A morte e o morrer são inerentes à existência humana ${ }^{(2)}$. As incertezas e a imprevisibilidade que se dispõem em volta do binômio morte-morrer compelem o ser humano a conviver com a sua presença desde o início ao estágio final do seu desenvolvimento ${ }^{(3)}$.

Partindo deste pressuposto, é justificado os indivíduos concederem à morte um caleidoscópio de significações. Os conflitos acarretados pela morte nos seres humanos, seja em relação à sua própria morte, à de seus familiares, ou mesmo no exercício profissional, deixam em relevo sentimentos diferentes exemplificados pela raiva, pela tristeza, pela barganha e pela negação, os quais carecem de discussão e de análise, de modo a propiciar um enfrentamento mais apropriado do processo de morte e morrer ${ }^{(4)}$.

As distintas formas de se encarar a morte e o morrer são encontrados nos vários períodos da História, traduzindo a diversidade de culturas que existiram no mundo, as variedades de pensamentos e as muitas individualidades que expressam sua ideia ${ }^{(5)}$. Com o rompimento dos paradigmas construídos socialmente pode-se ressaltar ainda a mutação dos contextos concernentes aos rituais funerários e à ascensão do âmbito hospitalar como principal cenário de morte em nossa realidade.

Este fato é justificado porque se vigora a necessidade de se esconder a morte e os mortos, ocultando-se a figura social do moribundo ${ }^{(6)}$. Neste sentido, percebe-se a constante institucionalização de idosos e enfermos na tentativa de evitar quaisquer vínculos afetivos com estes sujeitos.

Denota-se assim, a premência da implementação de ações direcionadas à preparação dos profissionais de saúde, especialmente, de enfermagem uma vez que se acercam a todo instante e de modo íntimo dos sentimentos, das frustrações e dos medos que são próprios da cultura e dos vividos de cada indivíduo que padece. Neste sentido, é relevante valorizar a dimensão emocional da equipe de enfermagem, destacando que antes de cuidar do outro que está morrendo, é preciso cuidar da emoção dos que cuidam ${ }^{(7)}$.

O interesse em estudar a morte emerge do propósito de se promover uma reflexão sobre o fenômeno da morte e do morrer tendo-se em vista as limitações inerentes aos seres humanos, de um modo geral, na convivência com este evento, que é inalienável à nossa realidade existencial.

Com este estudo, esperamos contribuir para o processo de desmistificação da morte e do morrer, tornando-o mais humano, através da substituição da curiosidade, do medo e da insegurança pela necessidade de reformular a assistência com desígnio de priorizar o enfrentamento do fato em detrimento de sua contestação. Esperamos, também, contribuir dando subsídio para outras pesquisas que relacionem esta problemática, tendo em vista a escassez de estudos congêneres.

Considerando a revisão sistemática da literatura como via de acesso ao conhecimento pré-existente e à necessidade dos autores de, a partir de resultados em evidência, refletirem acerca do que já se pesquisou sobre o tema em foco, formula-se a seguinte questão: quais as percepções, sentimentos e intervenções efetivas de estudantes e profissionais de enfermagem, diante o processo de morte e morrer no exercício profissional?

Partindo desta interrogativa, definimos como objetivos para este estudo: identificar o perfil das produções e analisar percepções, sentimentos e intervenções efetivas diante do processo de morte e morrer no exercício profissional evidenciados na produção científica da enfermagem no período de 1994 a 2009.

\section{METODOLOGIA}

Estudo de natureza qualitativa e descritiva, desenvolvido por meio de uma revisão sistemática da literatura: recurso que proporciona a incorporação das evidências científicas na prática da enfermagem, tanto na pesquisa, quanto na assistência $^{(8-9)}$.

A pesquisa compreendeu três fases: revisão sistemática da literatura; avaliação crítica dos artigos e metassíntese: método de pesquisa cujo objetivo é a análise minuciosa da teoria, métodos e resultados obtidos por estudos que utilizaram a abordagem metodológica qualitativa ${ }^{(10)}$.

A primeira fase: revisão sistemática da literatura realizada a partir de pesquisa bibliográfica eletrônica, utilizando as bases de dados: PubMed, Lilacs e SciELO a partir dos descritores: morte and enfermagem. Para seleção dos estudos, adotou-se como critérios de inclusão: pesquisas qualitativas realizadas pela enfermagem sobre o processo de morte e morrer, publicados em português, inglês ou espanhol no período entre 1994 e 2009. Foram identificados, inicialmente, 1.458 trabalhos.

Os estudos selecionados deveriam apresentar clareza quanto a alguns aspectos metodológicos, tais como: estudo original com amostra de sujeitos de ambos os sexos; desenho metodológico e enfoque teórico empregado na coleta e análise dos dados; amostras intencionais com critério de seleção explicitado e tamanho definido por processo de saturação de conteúdo; detalhamento da análise dos dados. Foram excluídos capítulos de livros, teses e dissertações, assim como estudos cujo objetivo central fosse o olhar dos pacientes diante da possibilidade da morte.

A segunda fase, a avaliação crítica dos estudos, foi feita com base no Critical Appraisal Skills Programme (CASP) (11) um check list que traça diretrizes para a avaliação da qualidade de pesquisas qualitativas. O CASP é composto por 10 itens que permitem classificar os artigos em categorias de acordo com estrutura metodológica. Os estudos foram classificados em categorias A e B.

A categoria A significa baixo risco de viés e deve atender pelo menos nove dos dez itens propostos: objetivo claro e justificado; desenho metodológico apropriado aos objetivos; 
apresentação e discussão dos procedimentos metodológicos; seleção da amostra intencional; descrição da coleta de dados: a escolha do instrumentos e o processo de saturação; relação entre pesquisador e pesquisado; procedimentos éticos; análise densa e fundamentada; resultados apresentados e discutidos, apontando o aspecto da credibilidade; descrição sobre as contribuições e implicações do conhecimento gerado pela pesquisa, bem como, suas limitações. A categoria B, por sua vez, corresponde a, pelo menos, cinco dos dez itens e significa que são atendidos parcialmente os critérios adotados, apresentando risco de viés moderado.

A terceira fase: metassíntese foi realizada por quatro revisores independentes. As categorias utilizadas na avaliação e na metassíntese foram obtidas por consenso entre os avaliadores. Os trabalhos selecionados foram lidos e avaliados a partir do método meta-etnográfico, ou seja, àquele que envolve indução e interpretação, trabalha com a ressignificação (translation) dos resultados entre os trabalhos, permitindo a compreensão e transferência de idéias, conceitos e metáforas ao longo dos diferentes estudos.

\section{RESULTADOS E DISCUSSÃO}

Embasados na leitura crítica dos títulos e dos resumos de todos os estudos localizados na busca eletrônica, 39 trabaIhos preencheram os critérios pré-estabelecidos e foram lidos na íntegra. Ao final desse processo, 10 trabalhos atenderam a estes discernimentos de inclusão. Este conjunto foi então submetido à avaliação de qualidade.

De acordo com os critérios de qualidade aplicados, três estudos foram classificados como A e sete como B. Os estudos selecionados são apresentados na Tabela 1, quanto aos autores, país do estudo, participantes, o método de coleta de dados, enfoques teóricos e nível de qualidade do estudo.

O Quadro 1 mostra o quantitativo de participantes do estudo: os trabalhos sobre o processo de morte e morrer incluem uma amostra diversificada, perfazendo aproximadamente 222 sujeitos entre acadêmicos e profissionais de enfermagem. Para produção dos dados, as estratégias foram várias: entrevistas semi-estruturadas ${ }^{(12-15,18,20)}$, grupo focal ${ }^{(18,21)}$, entrevista em profundidade $^{(19,21)}$, entrevista aberta ${ }^{(16)}$, dinâmicas de grupo e oficinas ${ }^{(17)}$.

\begin{tabular}{|c|c|c|c|c|}
\hline Autor/Ano & País & Participantes & Coleta de dados & $\begin{array}{l}\text { Nível da qualidade } \\
\text { dos estudos }\end{array}$ \\
\hline $\begin{array}{l}\text { Aguiar et al. } \\
(2006)^{(12)}\end{array}$ & Brasil & 10 enfermeiros assistenciais & Entrevista semi-estruturada & B \\
\hline $\begin{array}{l}\text { Barnieri; Hirdes } \\
\quad(2007)^{(13)}\end{array}$ & Brasil & 15 acadêmicos de Enfermagem & Entrevista semi-estruturada & B \\
\hline $\begin{array}{l}\text { Costa; Lima } \\
(2005)^{(14)}\end{array}$ & Brasil & $\begin{array}{l}26 \text { profissionais de enfermagem } \\
\text { (enfermeiros, técnicos e auxilia- } \\
\text { res de enfermagem) }\end{array}$ & Entrevista semi-estruturada & B \\
\hline $\begin{array}{l}\text { Shimizu } \\
(2007)^{(15)}\end{array}$ & Brasil & $\begin{array}{l}16 \text { profissionais de enferma- } \\
\text { gem (técnicos e auxiliares de } \\
\text { enfermagem) }\end{array}$ & Entrevista semi-estruturada & B \\
\hline $\begin{array}{l}\text { Poles; Bousso } \\
\left.{ }_{(2006)}\right)^{(16)}\end{array}$ & Brasil & 7 enfermeiros & Entrevista aberta & B \\
\hline $\begin{array}{l}\text { Bretãs; Oliveira; Yamaguti } \\
\qquad(2006)^{(17)}\end{array}$ & Brasil & 71 acadêmicos de Enfermagem & Dinâmicas de grupo/Oficinas & B \\
\hline $\begin{array}{l}\text { Gutierrez; Ciampone } \\
\qquad(2006)^{(18)}\end{array}$ & Brasil & $\begin{array}{l}11 \text { profissionais de enfermagem } \\
\text { (enfermeiros e técnicos de } \\
\text { enfermagem) }\end{array}$ & $\begin{array}{l}\text { Entrevista semi-estruturada e } \\
\text { grupo focal }\end{array}$ & A \\
\hline $\begin{array}{l}\text { Sadala e Silva } \\
{ }_{(2009)^{(19)}}\end{array}$ & Brasil & 14 acadêmicos de Enfermagem & Entrevista em profundidade & B \\
\hline $\begin{array}{l}\text { Oliveira; Brêtas; Yamaguti } \\
\qquad(2007)^{(20)}\end{array}$ & Brasil & 40 acadêmicos de Enfermagem & Entrevista semi-estruturada & A \\
\hline $\begin{array}{l}\text { Gutierrez; Ciampone } \\
(2007)^{(21)}\end{array}$ & Brasil & 12 profissionais de enfermagem & $\begin{array}{l}\text { Entrevista em profundidade, } \\
\text { grupo focal e oficinas }\end{array}$ & A \\
\hline
\end{tabular}

Quadro 1 - Perfil da produção sobre a percepção e enfrentamento do processo de morte e morrer no exercício profissional com estudantes e profissionais de enfermagem $(\mathrm{N}=10)$. 


\section{Percepções acerca da morte}

Os conceitos emergidos diante da morte e do processo de morrer desmembram-se em elementos como: passagem, separação e finitude. O elemento denominado passagem compreende uma concepção espiritual do tema, em que a pessoa tem a morte como transição entre o mundo material e o espiritual.

Eu acho que é uma passagem, uma etapa da vida, eu acho que nosso corpo fica e nosso espírito vai para outro lugar. ${ }^{(13)}$

A morte é uma continuidade, é separação e tristeza, é conseqüência da vida, é descanso, é dever cumprido ${ }^{(14)}$

A morte é uma coisa desconhecida. ${ }^{(20)}$

Morte é o fim de tudo, da manifestação da vida de uma pessoa. É um acontecimento biológico. (21)

A morte como passagem é a representação das crenças e convicções espirituais do ser humano ${ }^{(20)}$. Ela é vista como evento que ocorre com todos, num futuro, portanto supostamente desconhecido. A morte vista como o desconhecido traz à tona a emoção do medo, o mistério, o não familiar, que, é também associada a certo fascínio, pois oferece a possibilidade de desvendar algo que não se conhece e que pode ser mais instigante que a própria existência ${ }^{(16)}$.

A morte vinculada à idéia de finitude pode vir acompanhada de tristeza e revolta, considerando que ela interrompe a vida e reflete a idéia de pensar na morte fora de hora. Pode também ser arrostada com indiferença, fatalidade, após ter-se cumprido uma missão; poderá ser chamada de morte na hora certa ${ }^{(18)}$.

\section{Sentimentos relacionados à morte}

Mediante as diversas formas como os participantes do estudo percebem a morte e o morrer diversos sentimentos emergem. Estes devem ser exaustivamente explorados considerando que o autoconhecimento é um processo importante a ser averiguado a fim de melhor lidar com situações que impliquem manifestação de emoções profundas, principalmente as relacionadas com a morte. Os estudos revelam que os sentimentos são negativos: medo, perda, sofrimento, tristeza, angústia, impotência, frieza, dor, fracasso e erro.

A morte é carregada por um estigma muito grande, um misticismo, isso então cria uma concepção da morte como frustração e dor. (17)

A gente sente sim, e sofre bastante com a perda. (15)

Eu não consigo definir o que eu senti [...]. É mais do que uma frustração, é um sentimento muito ruim, é uma impotência. (14)

\section{Eu fico muito triste. (12)}

A vivência da frustração é angústia frente à situação irreversível: a perda. A sensação de frustração surge em conseqüência da própria formação direcionada a recuperar a vida. A perda do controle da situação, a iminência da morte, apesar de todos os recursos tecnológicos, faz com que os profissionais se defrontem com suas limitações. Ao reconhecê-las, é como se a habilidade profissional estivesse sendo testada, como se a manutenção da vida dependesse da competência da equipe responsável pelo paciente ${ }^{(17)}$.

Há também os sentimentos de tristeza e impotência que variam de acordo com as estratégias de cuidado que são utilizadas. Aqueles que se envolveram mais com o paciente, após maior convivência, revelam um profundo sentimento de tristeza e angústia ligado a esse cuidado. Os dados encontrados são similares aos dados da literatura. Sentimentos de frustração e impotência nesse cuidado ineficaz, que acaba no momento da morte do paciente; assim como a própria percepção do despreparo técnico e incapacidade de lidar com os próprios sentimentos são relatados tanto por estudantes como por profissionais de enfermagem ${ }^{(12-21)}$.

\section{Estratégias de enfrentamento diante da morte}

A dificuldade em se relacionar com pacientes com prognóstico de morte se deve em parte às características apresentadas pelo paciente nesta fase e, principalmente, à dificuldade interna que sentem em lidar com o problema.

De um modo geral, é perceptível que aos estudantes e profissionais de enfermagem não é permitido viver o luto de outros, talvez, na tentativa de se protegerem ou então porque não estão preparados para conviver com essas manifestações somáticas e emocionais. Eles acreditam que sua postura deva ser firme e que reconhecer o seu sofrimento significa ferir sua índole. Ainda há a visão de que o profissional deva ser "frio" ou indiferente na situação de morte.

Mentalmente, eu procuro separar um pouco a vida particular de dentro da UTI, porque senão a gente entra em parafuso. Eu procuro separar. (16)

Pra mim, é natural, eu já aprendi a lidar tanto com a vida como com a morte. (17)

O enfrentamento da morte tem por princípio o desenvolvimento da sua própria compreensão (de sua subjetividade), tendo por dimensão os conceitos de irreversibilidade e universalidade. $\mathrm{A}$ irreversibilidade refere-se à compreensão de que o corpo físico não pode viver depois da morte, portanto, inclui o reconhecimento da impossibilidade de mudar o curso biológico ou de retornar a um estado prévio. A universalidade refere-se à compreensão de que tudo que é vivo morre ${ }^{(13,16)}$.

É relevante destacar que o enfrentamento do sofrimento causado pela perda de um paciente pode ser construtivo, desde que se tenha auto-estima elevada e maturidade para encarar este tipo de atividade, orientada pela sua responsabilidade e ética profissional. No entanto, para impedir o sofrimento é necessário que tanto o acadêmico como o profissional busque maneiras para lidar com ele, negando a sua presença ou acostumando-se com a sua existência ${ }^{(18)}$. 


\section{CONCLUSÃO}

Independentemente do método e da forma com que os dados foram coletados, os sujeitos apresentaram percepções, sentimentos e enfrentamentos semelhantes a respeito do processo de morte e morrer.

Evidenciou-se a partir da literatura que acadêmicos e profissionais de enfermagem percebem este processo como passagem, separação e finitude. Percebeu-se o despreparo, que aparece ao defrontar-se com a situação real. Para todos, foi uma experiência dolorosa. Para alguns, resultou em aprendizado e superação. A evidência da tensão entre o ideal pessoal de cuidar do paciente e a realidade particular que se vive ao cuidar aparece nos discursos e estão permeados de sentimentos de frustração e impotência.

$\mathrm{O}$ estudo demonstra que as intervenções mais efetivas diante deste problema é o desenvolvimento de estratégias de enfrentamento que variam de acordo com a realidade de cada indivíduo: o contexto e o vivido de cada ser. Para os estudantes e profissionais de enfermagem são consideradas efetivas a desvalorização do biologicismo em detrimento a subjetividade que permeia a existência humana em que a morte é inevitável, considerando que o homem é um ser-para-a-morte.

Dentre as evidências práticas relacionadas às estratégias de enfrentamento destaca-se nos estudos: a separação das emoções vividas no trabalho da vida particular; a resistência psíquica à agressão que constituem determinadas atividades inerentes ao trabalho, em especial, àquelas relacionadas à morte.

\section{REFERÊNCIAS}

1. Corrêa JA. Filosofia frente \& verso. São Paulo; 2008.

2. Ross EK. Sobre a Morte-Morrer. 8 ed. São Paulo: Martins Fontes; 2000

3. Zorzo JCC. O processo de morte e morrer da criança e do adolescente: vivências dos profissionais de enfermagem [dissertação]. Ribeirão Preto: Escola de Enfermagem de Ribeirão Preto, Universidade Federal de São Paulo; 2004.

4. Agra LMC, Albuquerque LHM. Tanatologia: uma reflexão sobre a morte e o morrer. Pesquisa Psicológica [serial online] 2008 [cited 2009 out 19]; 1(2). Avaliable from: http:// www.pesquisapsicologica.pro.br

5. Rezende E. Diversas visões da morte e uma perspectiva atual. In: Escudeiro A. Tanatologia: conceitos - relatos reflexões. Fortaleza (CE): LC gráfica e editora; 2008.

6. Lessa C. Trabalhando com a morte. 2 ed. São Paulo: Scarpitta; 1995.

7. Machado WCA, Leite JL. Eros e Thanatos: a morte sob a ótica da enfermagem. São Caetano do Sul: Yenis; 2006.

8. Galvão CM, Sawada NO, Trevizan MA. Revisão sistemática: recurso que proporciona a incorporação das evidências na prática da enfermagem. Rev. Latino-Am. Enfermagem 2004; 12(3): $1-9$

9. Abreu LO, Munari DB, Queiroz ALB, Fernandes CNS. O trabalho de equipe em enfermagem: revisão sistemática da literatura. Rev Bras Enferm 2005; 58(2):203-7.

10. Noblit GW, Hare RD. Meta-ethnography: synthesizing qualitative studies. Newbury Park: Sage;1988.

11. Critical Appraisal Skills Programme (Casp). Making sense of evidence. London: University of Oxford; 2002.

12. Aguiar IS, Veloso TMC, Pinheiro AKB, Ximenes LB. O envolvimento do enfermeiro no processo de morrer de bebês internados em Unidade Neonatal. Acta paul. enferm.2006; 19(2): 131-7.
13. Bernieri J, Hirdes A. O preparo dos acadêmicos de enfermagem brasileiros para vivenciarem o processo morte-morrer. Texto Contexto Enferm 2007; 16(1):89-96.

14. Costa JC, Lima RCG, Luto da equipe: revelações dos profissionais de enfermagem sobre o cuidado à criança/adolescente no processo de morte e morrer. Rev. Latino-Am. Enfermagem 2005; 13(2):151-7.

15. Shimizu HE. Como os trabalhadores de enfermagem enfrentam o processo de morrer. Rev Bras Enferm 2007; 60(3):245-52

16. Poles K, Bousso RS. Compartilhando o processo de morte com a família: a experiência da enfermeira na UTI pediátrica. Rev. Latino-Am. Enfermagem [serial on line]. 2006 Abr [cited 2010 Abr 25]; 14(2): 207-13. Avaliable from: http://www.scielo.br/scielo.php?script $=$ sci arttext\&pid $=$ S0104\&lng $=$ pt.

17. Brêtas JRS, Oliveira JR, Yamaguti L. Reflexões de estudantes de enfermagem sobre morte e o morrer. Rev Esc Enferm USP [serial on line]. 2006 Dec [cited 2010 Apr 25]; 40(4): 477-83. Available from: http://www.scielo.br/ scielo.php?script $=$ sci arttext $\&$ pid $=$ S0080.52

18. Gutierrez BAO, Ciampone MHT. Profissionais de enfermagem frente ao processo de morte em unidades deterapia intensiva. Acta paul. Enferm 2006; 19(4):456-61.

19. Sadala MLA, Silva FM. Cuidando de pacientes em fase terminal: a perspectiva de alunos de enfermagem. Rev. esc. enferm. USP 2009; 43(2):287-94.

20. Oliveira JR, Brêtas JRS, Yamaguti L. A morte e o morrer segundo representações de estudantes de enfermagem. Rev. esc. enferm. USP 2007; 41(3):386-94.

21. Gutierrez BAO, Ciampone MHT. O processo de morrer e a morte no enfoque dos profissionais de enfermagem de UTIs. Rev. esc. enferm. USP 2007; 41(4): 660-7. 